\title{
El Plan Prebisch de 1955, los dilemas del desarrollo argentino y las controversias en torno a los legados económicos del peronismo ${ }^{1}$
}

por

\author{
Claudio Belini²
}

CONICET-Universidad de Buenos Aires

\begin{abstract}
Este artículo analiza las controversias en torno a los legados económicos del peronismo que estallaron a partir de la presentación del Plan Prebisch de 1955. El trabajo estudia las respuestas que brindaron economistas y políticos de cuatro tradiciones ideológicas distintas (izquierdas, nacionalismo, liberalismo y peronismo), a los diagnósticos realizados por Raúl Prebisch sobre el estado de la economía argentina. Se examinan las ideas económicas predominantes en los años cincuenta y los límites con que los actores comprendieron los dilemas que enfrentaba la Argentina como economía semi-industrializada. Se sostiene que estos debates definieron una agenda que perduraría hasta el ascenso del desarrollismo de Arturo Frondizi en 1958 y, al mismo tiempo, tuvieron una prolongada influencia en las interpretaciones historiográficas sobre la economía peronista.
\end{abstract}

Palabras Claves: políticas económicas; ideas económicas; Peronismo; Argentina.

Cómo citar este artículo / Citation: Belini, Claudio, "El Plan Prebisch de 1955, los dilemas del desarrollo argentino y las controversias en torno a los legados económicos del peronismo", Revista de Indias, LXXVIII/273 (Madrid, 2018): 593-629. https://doi.org/10.3989/ revindias.2018.018.

1 Una versión previa de este trabajo fue presentada en el workshop "Peron in exile", Hoover Institution, Stanford University, 9 y 10 de febrero de 2015, organizado por Herbert S. Klein con la colaboración de José Carlos Chiaramonte. Agradezco los comentarios recibidos en esa oportunidad y los de los evaluadores de la Revista de Indias.

2 Instituto Ravignani. Programa de Estudios de Historia Económica y Social Americana. Púan 480, 4 piso, Oficina 418-419. Buenos Aires (1406), Argentina. claudiobelini@conicet. gov.ar, ORCID iD: http://orcid.org/0000-0002-2335-937X. de uso y distribución Creative Commons Reconocimiento 4.0 Internacional (CC BY 4.0). 
En enero de 1956, un periodista de la conservadora revista Reader's Digest, publicó una nota titulada "What Peron Cost Argentina" en la que asimilaba al peronismo a las dictaduras que entonces dominaban en América Latina, sosteniendo que Perón había dilapidado «la mejor oportunidad que ha tenido la Argentina de convertirse en un gran país» ${ }^{3}$. El autor no dudaba que el país, dotado de ricos recursos naturales y «predestinado a la grandeza», reencontraría muy pronto el camino de progreso y la democracia. Su nota, plagada de los «clichés» que sobre los regímenes autoritarios latinoamericanos difundía la prensa norteamericana y el Departamento de Estado, revelaba una nueva realidad marcada por dificultades económicas, la incredulidad de los ciudadanos argentinos y el desconcierto de sus sectores dirigentes.

En efecto, entre 1946 y 1955 la economía argentina había transitado de la prosperidad de la inmediata posguerra al estallido de una crisis estructural. Inicialmente, la Argentina se vio beneficiada por un conjunto de circunstancias excepcionales como los altos precios mundiales para la carne y los cereales, y la acumulación de reservas en oro y divisas sin precedentes debido a las restricciones impuestas a la importación durante la Segunda Guerra Mundial. Por su parte, el sector manufacturero, que a partir de 1930 se había transformado en el motor de la economía, continuaba creciendo sin interrupciones, ofreciendo una demanda sostenida de mano de obra. A comienzos de los años cincuenta, la Argentina enfrentaba un grave desequilibrio externo provocado por el estancamiento de los saldos exportables, la caída de los precios mundiales de los cereales, y la escasez de dólares para renovar y ampliar el stock de capital en la industria, el agro y los transportes. La inflación, que había sido impulsada por causas internacionales durante la década de 1940, mostraba un ritmo ascendente, amenazando erosionar el nuevo patrón distributivo impuesto por el peronismo. Durante la década de 1950, la economía argentina sufriría una doble compresión de los términos del intercambio y del poder de compra de las exportaciones. Si bien estos problemas eran comunes a las economías latinoamericanas más grandes, la Argentina los padecería de modo más intenso. Como resultado, entre 1946 y 1960, el PBI per cápita argentino crecería muy lentamente (un 1,2\% anual), en comparación con Brasil y México $(3,4 \%$ y $2,8 \%$ respectivamente), países que además tenían tasas de crecimiento demográfico notablemente más altas (véase cuadros 1 y 2 del ANE$\mathrm{xO})^{4}$.

\footnotetext{
3 Scully, 1956: 11-12

4 Cálculos propios basados en Maddison, 1990. Sobre América Latina en los años cincuenta, Bulmer Thomas, 1994: 276-297.
} 
El deterioro de la posición externa argentina condujo a los analistas a pensar al período peronista como un momento clave a la hora de explicar el modesto desempeño de la economía argentina en la segunda posguerra. Las interpretaciones son variadas y hasta opuestas. Mientras autores inspirados en la teoría neoclásica han buscado una explicación en la orientación errada de las políticas peronistas que habría conducido al país a la autarquía, descartando las oportunidades abiertas por la reanudación del comercio mundial ${ }^{5}$, otras interpretaciones influenciadas por el estructuralismo latinoamericano o bien por diversas corrientes de la tradición marxista, han criticado al gobierno peronista por la falta de un plan orgánico de industrialización centrado en las industrias básicas y la perduración del régimen de propiedad de la tierra dominado por el latifundió ${ }^{6}$.

En los últimos años varios autores han marcado, con diferentes énfasis, que el período peronista no fue el principal momento de ampliación de la brecha con las naciones desarrolladas 7 . Estudios sobre las políticas macroeconómicas han coincidido en argumentar, con algunas variantes, que durante el peronismo predominó un enfoque cuyo centro fue la distribución del ingreso antes que el desarrollo económico. De cualquier manera, estos trabajos acuerdan en sostener que a partir de la década de 1950 las políticas peronistas se modificaron con diferente grado de éxito en respuesta a la crisis de la balanza de pagos y la inflación ${ }^{8}$.

El propósito de este artículo es analizar cómo percibieron los actores la crisis que azotó a la economía argentina a partir de los años cincuenta y cómo se evaluó la herencia económica del peronismo. En particular, nos focalizamos en el estudio de las controversias que sobre esa temática surgieron a partir de la presentación, entre octubre de 1955 y enero de 1956, de los informes sobre el estado económico del país elaborados por Raúl Prebisch ${ }^{9}$. Estos debates,

5 Díaz Alejandro, 1975: 111-129. Lewis, 1993: 219-257. Cortés Conde, 2006: 141-204.

${ }^{6}$ Ferrer, 1963; 1977: 13-33. Peralta Ramos, 1978: 79-101. Basualdo, 2006: 34-53.

7 El punto es claro si recordamos que a mediados de la década de 1970 la Argentina inició una etapa de estancamiento y que le tomaría veinte años a la economía local superar el PBI per cápita de 1974. Belini y Korol, 2012: 231-233. Para enfoques que resaltan varios momentos de divergencia, véase Della Paolera y Taylor, 2003. Llach y Lagos, 2014.

8 Gerchunoff, 1989: 59-85. Gerchunoff y Antúnez, 2002: 124-205. Rougier, 2012: 136160. Belini, 2014: 105-148.

9 Para un trabajo pionero sobre las políticas de los años cincuenta, véase Eshag y Thorp, 1974: 83-91. Sobre los debates económicos de la época, Cuminsky, 1962: 129-153 y, especialmente, Di Tella, 1979. Para estudios sobre el plan y las controversias véase Sikkink, 1988: 94-100. Alonso, 1989: 3-11. Gilbert, Tenewicki y Rougier, 2000. Altamirano, 2001: 51-54. Sobre los debates en torno a la política industrial entre 1955 y 1958, Belini, 2013: 117-161. 
en los que intervinieron actores políticos y económicos, se enmarcaron en las controversias en torno a las interpretaciones del peronismo y la construcción de un orden político legítimo en reemplazo del sistema peronista ${ }^{10}$. Nos interesa analizar las discusiones en torno a la economía peronista y sus legados por dos razones: en primer lugar, estos debates definieron una primera interpretación sobre los resultados económicos del peronismo e influyeron en las interpretaciones que historiadores y economistas han dado sobre ese tema. En segundo lugar, esas controversias revelaron las ideas económicas predominantes en la época y definieron una agenda que perduraría hasta la puesta en marcha de las políticas desarrollistas por el presidente Arturo Frondizi en 1958.

En este trabajo sostenemos que el debate en torno a los legados económicos del peronismo estuvo signado por un claro tono político. Una de las razones de ello fue, como se sabe, la breve pero crucial intervención de Raúl Prebisch, primer gerente general del Banco Central y consejero económico de los gobiernos conservadores de la década de 1930. Como advirtió Halperín, el rechazo a la figura del secretario de la Comisión Económica para América Latina (CEPAL) reveló el marcado provincialismo político en que se había sumergido la Argentina peronista ${ }^{11}$. El trabajo sostiene que los problemas que enfrentaba la economía argentina en los años cincuenta marcado por la crisis crónica del balance de pagos, la inflación y los desequilibrios propios de una industrialización incompleta, por cierto compartidos con desigual intensidad por otras economías latinoamericanas según lo revelaban los estudios de la CEPAL, no fueron del todo comprendidos por los actores políticos y económicos. Esta dificultad para interpretar la nueva realidad económica y el fortalecimiento de concepciones nacionalistas y «autarquizantes» imprimieron sus particularidades al debate. En ese marco, las interpretaciones sobre la herencia económica del peronismo se caracterizaron por presentar una crítica aguda a lo que consideraban una oportunidad perdida. Pero, con la excepción de los economistas liberales, el peronismo fue censurado más por lo que no había realizado en el sendero de la autarquía, que por las rectificaciones que introdujo en su estrategia económica en respuesta a la crisis de 1952. Si bien los peronistas era objeto de fuerte persecución, ofrecieron diversas respuestas a estas críticas, algunas de ellas reveladoras de los dilemas que enfrentaba la economía local y que se fundaban en la experiencia de gobierno a partir de 1952.

10 Sarlo, 2001: 19-42. Spinelli, 2005: 53-128. Altamirano, 2011: 61-97.

11 Halperín, 1972: 91. Sobre el estructuralismo de Raúl Prebisch y la CEPAL, véase Love, 1996: 237-246. Fitzgerald, 2000: 58-97. 
La primera parte del artículo estudia, en el contexto del desarrollo del estructuralismo cepaliano, los informes de Prebisch sobre la economía argentina. Este plan fue el primer documento oficial que realizó un balance sobre la economía peronista pocas semanas después de la caída de Perón. En el segundo apartado analizamos los balances sobre el desempeño de la economía argentina en los años peronistas desde cuatro tradiciones o corrientes ideológicas: los sectores progresistas, la tradición nacionalista, la corriente liberal y el peronismo. En este sentido, nos apartamos de estudios previos que han analizado esas controversias a partir de intervenciones individuales sin observar que el Plan Prebisch fue el catalizador de debates entre tradiciones ideológicas más amplias y que solo pueden comprenderse en ese marco ${ }^{12}$. En la tercera parte, planteamos la convergencia de varios grupos en la «síntesis frondicista» o el intento fallido del dirigente radical Arturo Frondizi de ofrecer una fórmula superadora de las controversias económicas de los años cincuenta. Por último, realizamos algunas consideraciones finales sobre ese debate, su impacto en el escenario político argentino y en las interpretaciones historiográficas.

\section{El Plan Prebisch de 1955, Primer balance de la eConomía PERONISTA}

El derrocamiento de Perón en 1955 inauguró las discusiones en torno a los legados de casi diez años de gobierno. La alianza antiperonista se fundaba en la oposición a Perón, pero estaba lejos de constituir un grupo de sólidas posiciones sobre el orden político y económico que debía imponerse luego de la victoria. El líder de la rebelión, el general Eduardo Lonardi, encabezaba un pequeño grupo de militares y civiles nacionalistas que ambicionaba purgar a la Argentina de los males de la demagogia y el autoritarismo que adjudicaban al liderazgo de Perón, pero no rechazaba el enfoque de política económica y social implantado por éste. En cambio, otra facción más importante, se proponía «desperonizar» políticamente al país y desmantelar las políticas intervencionistas y dirigistas del peronismo.

12 Cuminsky, 1962: 145-149, recopila algunas referencias sobre el plan, en el marco de las discusiones económicas de los años cincuenta. Gilbert, Tenewicki y Rougier, 2000 analizan los debates sobre el Plan Prebisch a partir de intervenciones puntuales de actores políticos y algunas publicaciones económicas. Por su parte, Sikkink, 1988: 98-100, estudia las reacciones de las corporaciones empresarias y de líderes políticos. 
Retomando una invitación formulada por Perón, Lonardi nombró a Prebisch, por entonces secretario general de la CEPAL, asesor financiero y económico. Su designación parecía indicar que el nuevo gobierno tomaba nota de los cambios operados en la economía argentina. En efecto, a fines de la década de 1940, Prebisch había evolucionado hacia posturas heterodoxas, al formular los fundamentos del estructuralismo cepaliano (lo que se conocería como el Manifiesto Latinoamericano) que argumentó a favor de la industrialización de las economías primario exportadoras y de la aplicación de programas de activa intervención estatal para favorecer el cambio estructural. Bajo su dirección la CEPAL se concentró en el análisis de los procesos de industrialización, la definición de programas de desarrollo económico y el fenómeno, cada vez más importante, de la inflación como manifestación de los desequilibrios estructurales de las economías latinoamericanas ${ }^{13}$. El complejo desenvolvimiento del sector industrial y la inflación constituían aspectos muy relevantes a la hora de analizar la economía argentina que, a diferencia de la mayor parte de las economías de la región, mostraba una desaceleración de la tasa de crecimiento y el incremento de la restricción externa ${ }^{14}$.

El estructuralismo cepaliano había tenido menor impacto en la Argentina que en Brasil y Chile, pero las ideas no eran desconocidas. Incluso, entre los economistas e ingenieros que integraron los equipos peronistas las concepciones de matriz cepaliana fueron bien recibidas ${ }^{15}$. Varios documentos presentados por el gobierno de Perón en reuniones internacionales retomaban las tesis cepalianas a favor de la industrialización y la denuncia del deterioro de los términos del intercambio como manifestación de la capacidad de los países industrializados para retener los frutos del progreso tecnológico y del proteccionismo agrario ${ }^{16}$. Este tema, que no ha sido abordado por la historiografía, requiere un análisis imposible de ser desarrollado aquí, pero revela que el desembarco de Prebisch en Buenos Aires tenía por detrás una historia de contactos e influencias.

Claro que lo que modificaría esta convergencia, que en esos años estuvo limitada al plano de las ideas, sería la actuación de Prebisch en la preparación

13 CEPAL, 1998, vol. 1: 9-29. Fitzgerald, 2000: 58-69.

14 Entre 1945 y 1954, América Latina creció a una tasa del 5,8\% anual y las importaciones ascendieron a un ritmo del 7,5\%. CEPAL, 1998, vol. 1: 17

15 Emilio Llorens, "Notable cambio de frente", Revista de Economía Argentina, agosto-septiembre de 1950: 168.

16 Ministerio de Finanzas, 1953-55, acta 41, 26/3/53, "El quinto período de sesiones de la CEPAL y los proyectos de la posición argentina”, documento anexo. Véase también, Ministerio de Relaciones Exteriores..., 1953: 9-47. Para una interpretación que sostiene la falta de impacto de las ideas de Prebisch en la Argentina peronista, véase Sikkink, 1988: 92-94. 
de un balance y recomendaciones de política económica para el gobierno argentino. El secretario de la CEPAL se rodeó de un grupo de economistas, la mayoría de ellos ortodoxos, con el objetivo de elaborar sus informes ${ }^{17}$. Al parecer, ello se debió a los lazos que Prebisch mantenía con varios de ellos con anterioridad a 1948, cuando se había trasladado a Chile. Finalmente, Prebisch presentó sus propuestas en tres trabajos sucesivos: "Informe preliminar sobre la situación económica", publicado en octubre de 1955, y "Moneda sana o inflación incontenible" y "Plan de Restablecimiento Económico", difundidos en enero de $1956^{18}$. El primero encendió las polémicas, ya que presentó un balance muy crítico de la economía argentina:

La Argentina atraviesa por la crisis más aguda de su desarrollo económico, más que aquella que el presidente Avellaneda hubo de conjurar ahorrando sobre el hambre y la sed, y más que la del 90 y que la de hace un cuarto de siglo, en plena depresión mundial. El país se encontraba en aquellos tiempos con sus fuerzas productivas intactas. No es este el caso de hoy: están seriamente comprometidos los factores dinámicos de su economía y será necesario un esfuerzo intenso y persistente para restablecer su vigoroso ritmo de desarrollo económico ${ }^{19}$.

Según el secretario de la CEPAL, la economía argentina estaba estancada desde 1948, se avecinaba una nueva crisis de balanza de pagos (con un déficit de 186 millones de dólares) en tanto que los compromisos de divisas con el exterior alcanzaban 757 millones. La crisis era el resultado de la mala orientación de las políticas peronistas en al menos cinco aspectos. En primer lugar, la nacionalización del comercio exterior a través del Instituto Argentino para la Promoción del Intercambio (IAPI) y la revaluación del tipo de cambio habían desalentado la producción agraria, derrumbándola hasta el 64\% del volumen alcanzado en 1939. Esto implicaba que el país veía reducida su capacidad de generar dólares y la posibilidad de importar equipos y maquinarias para incrementar la productividad en el campo y la industria. En segundo lugar, la planificación peronista había sido muy ineficiente, al orientar la inversión estatal hacia gastos de consumo. El país requería una gran inversión

17 Los colaboradores fueron los economistas Julio Alizón García, Carlos Coll Benegas, Adalbert Krieger Vasena, Eusebio Campos, Pascual Martínez y Carlos Brignone. A ellos se sumó el ingeniero Francisco García Olano, de posturas heterodoxas. Alizón García y Coll Benegas conocían a Prebisch desde su desempeño en el Banco Central. El primero, que había trabajado en CEPAL pero era de tendencia liberal, fue designado ministro de Finanzas en 1955 y, al año siguiente, presidente del Banco Central. Por su parte, Krieger asumiría el Ministerio de Hacienda en 1957.

18 Prebisch, 1955a; 1956.

19 Prebisch, 1956: 11. 
para modernizar el sistema de transportes e impulsar nuevas industrias en el momento en que los dólares escaseaban. Un tercer error había sido la política de industrialización que se había orientado hacia las ramas de bienes de consumo final, olvidando el desarrollo de la siderurgia, la rama química, la producción de papel y celulosa. En definitiva, la industrialización peronista tenía «bases precarias». En cuarto lugar, el estado había pretendido «regular la conducta de los individuos en el proceso económico». El resultado era una «intervención excesiva y desordenada» que perturbaba la actividad económi$\mathrm{ca}^{20}$. Por último, la puesta en marcha de políticas monetarias y crediticias expansivas, acompañadas de «aumentos masivos de sueldos y salarios» en un marco de estancamiento de la productividad, habían dado origen a una persistente inflación.

Las recomendaciones iniciales de Prebisch consistían en la devaluación de la moneda para alentar las exportaciones y eliminar el déficit del IAPI; el reforzamiento del control sobre las importaciones; el aliento a la producción de petróleo y electricidad; la aplicación de una política antiinflacionaria que moderara los aumentos de precios resultantes de la devaluación, especialmente de sueldos y salarios para evitar que la reanudación de la inflación redujera los incentivos al sector agrario. También proponía la discusión sobre la conveniencia de solicitar apoyo financiero de instituciones extranjeras.

El programa de Prebisch se completó, en enero de 1956, con la publicación de dos documentos, "Moneda sana o inflación incontenible" y "Plan de Restablecimiento Económico", que contenían recomendaciones específicas como la convocatoria al capital extranjero, el retorno al comercio multilateral, el ingreso al Fondo Monetario Internacional y al Banco Mundial ${ }^{21}$. Gran parte de las propuestas estaban centradas en el problema de la inflación. Prebisch entendía que era vital desarmar la inflación de costos para lograr la estabilidad monetaria. Sólo así se podría alentar el ingreso de capitales extranjeros y se promovería el incremento de la capacidad productiva y exportadora del país. La receta antiinflacionaria se concentraba en el ajuste fiscal, la privatización empresas públicas y la limitación de los aumentos salariales a incrementos de la productividad. Con esta postura, el secretario de la CEPAL parecía adherir al diagnóstico «monetarista» de la inflación, apartándose de la interpretación estructuralista defendida por los economistas de la CEPAL. Esta postura tuvo sus consecuencias incluso en el interior de ese organismo. La posición de Prebisch en Argentina reforzó a quienes sostenían la explicación «monetaris-

\footnotetext{
20 Ibidem: 17-46.

21 García Heras, 2008: 31-60.
} 
ta» de la inflación frente a los heterodoxos. Según Celso Furtado, esta interpretación debilitó el liderazgo de Prebisch en la CEPAL ${ }^{22}$.

Si estas medidas configuraban un programa ortodoxo, Prebisch también propiciaba una activa intervención del estado para alentar el desarrollo económico mediante la resolución de los «cuellos de botella». En este punto, Prebisch retomaba el ideario cepaliano al sostener que la Argentina debía desarrollar las industrias básicas (siderurgia y química), el complejo automotor y otras industrias metalmecánicas, la explotación petrolera y la producción eléctrica ${ }^{23}$.

Poco después, el gobierno designó una comisión, integrada por economistas, empresarios y sindicalistas, que analizó y aprobó el plan, dando prioridad al reequipamiento del transporte ferroviario y automotor, y al incremento de la electricidad. El dictamen resaltó las dimensiones ortodoxas del programa de Prebisch, al señalar que debía revertirse la «industrialización desordenada y antieconómica» para evitar que fuera «un pesado lastre en la economía del país», y aseverar que «el estado ha sido, es y será en todos los tiempos y en todas las latitudes, un mal administrador» ${ }^{24}$.

El gobierno de la autodenominada «Revolución Libertadora» aplicó parcialmente las recomendaciones de Prebisch; en octubre de 1955 devaluó la moneda, inició la liquidación del IAPI y el levantamiento de los controles de precios. Entre 1956 y 1957, se negoció el retorno al comercio multilateral por medio de una serie de acuerdos con los principales socios comerciales con los que Argentina tenía deudas comerciales en el marco de los convenios bilaterales y que dio origen al Club de París. También se emplearon préstamos internacionales para financiar proyectos estatales en el área del petróleo y la siderurgia. Con la excepción de un breve período en que la conducción económica estuvo en manos del keynesiano Eugenio Blanco, el gabinete económico del general Pedro Eugenio Aramburu provino fundamentalmente de la ortodoxia. Así se sucedieron los economistas Roberto Verrier, Julio Alizón García y Adalbert Krieger Vasena. A pesar de este predominio, el gobierno cívico militar estuvo muy lejos de «liberalizar» la economía. De cualquier modo, el Plan Prebisch ofreció una primera interpretación sobre los legados del peronismo e inauguró las controversias sobre el futuro económico del país.

22 Prebisch, 1956: 11-28. Furtado, 1988: 159.

23 Prebisch, 1956: 39-43. Esta convivencia entre medidas ortodoxas y estructuralistas es señalada por Eshag y Thorp, 1974: 84. Alonso denomina esos objetivos como «el costado desarrollista» del plan, Alonso, 1989: 4. Gilbert, Tenewicki y Rougier, 2000: 4.

24 Comisión Asesora Honoraria de Economía y Finanzas, 1956: 9 y 18. 


\section{CuATro INTERPRETACIONES SOBRE LA ECONOMÍA PERONISTA}

\subsection{Los sectores progresistas}

A mediados de la década de 1950, las principales fuerzas políticas en el campo de las izquierdas eran muy críticas de las políticas peronistas. Entre ellas, se ubicaban con sus diferencias la Unión Cívica Radical, el Partido Socialista y el Partido Comunista. El primero era el principal partido opositor, y aunque estaba dividido ideológicamente entre la corriente izquierdista denominada intransigencia y el unionismo, levantó un programa de reformas económicas y sociales que proponía la superación del peronismo «por izquierda». Arturo Frondizi, presidente del Comité Nacional, era un importante líder intransigente y sostenía la Carta de Avellaneda de 1945, que propiciaba la nacionalización de los transportes, el control estatal de la banca, la reforma agraria y la participación de los trabajadores en las ganancias de las empresas. Los cambios introducidos por Perón en su enfoque a partir de 1952 - la política antiinflacionaria y el llamado al capital extranjero - habían sido muy resistidos por los radicales. En 1954, Frondizi encabezó el rechazo al contrato con la Standard Oil para la explotación petrolífera y publicó Petróleo y Política, donde analizaba en clave anti-imperialista la historia del petróleo argentino. En junio de 1955, poco antes de la caída de Perón, Frondizi denunció que «los privilegios económicos representados por el latifundio, el monopolio y la penetración imperialista han actuado como factores paralizantes» del progreso del país ${ }^{25}$.

El radicalismo dio la bienvenida a la «Revolución Libertadora» pero poco después expresó sus disidencias. Si el derrocamiento del gobierno peronista y la restauración de las libertades públicas era motivo de apoyo, el diagnóstico de Prebisch fue rechazado de plano: «El radicalismo sabe que la situación económica es grave, pero de ninguna manera acepta que sea catastrófica ni fatal». Para Frondizi este diagnóstico errado inducía a una política económica que no coincidía con «los intereses nacionales y populares del país» ${ }^{26}$. Según su opinión, el gobierno debía evitar la desocupación y contener la inflación, realimentada por la devaluación. Por tanto, reclamaba que los costos del ajuste fueran soportados por los sectores de altos ingresos por medio de una mayor presión impositiva ${ }^{27}$.

25 Frondizi, 1956: 27, Comité Nacional de la Unión Cívica Radical, "La UCR y el 16 de junio".

26 Ibidem: 46-47, "El radicalismo y la actual situación social argentina" (30/11/1955).

27 Ibidem: 45-58. 
Cuando Prebisch presentó sus planes definitivos, en enero de 1956, los debates internos se ampliaron. Mientras que la corriente intransigente formuló críticas, los unionistas manifestaron un acuerdo parcial con la propuesta oficial. José Liceaga, dirigente intransigente, presentó la visión más crítica al tiempo que inauguró una revaluación parcial de la economía peronista. En el primer aspecto interpretó el plan como una reiteración del Pacto Roca-Runciman y de las políticas implementadas por Federico Pinedo y Prebisch en la década del treinta, que buscaban reacomodar la economía argentina en «íntima relación de dependencia para con el capitalismo internacional» ${ }^{28}$. Este propósito obligaba a Prebisch a presentar la imagen de una crisis económica, cuya profundidad era mucho menor que las de 1890 y 1930, entre otras cosas por «el desarrollo industrial que en los últimos veinte años aportó una nueva fisonomía a nuestro régimen económico» ${ }^{29}$. El análisis de Prebisch sobre el origen de la inflación era otro ejemplo de su orientación ya que se responsabilizaba al déficit de las empresas públicas y los aumentos de salarios, ocultando el poder de los monopolios y del latifundio. En suma, el Plan Prebisch constituía una «tentativa de reincidencia» que propiciaba el retorno a viejas fórmulas para salvaguardar, como en 1933, los intereses de la clase terrateniente. Si bien Liceaga no dejaba de resaltar los errores del peronismo, consideraba que ellos no impugnaban muchos de sus principios ni de los instrumentos, los que aplicados correctamente habrían podido transformar la estructura económica argentina.

El origen de la inflación y el papel del capital extranjero fueron dos temáticas que merecieron mayor atención por parte de los representantes del radicalismo intransigente en la Junta Consultiva Nacional, un organismo integrado por representantes de las fuerzas políticas no peronistas. Retomando el análisis de Liceaga, Óscar Alende y Óscar López Serrot cuestionaron el diagnóstico sobre la «inflación de costos» de Prebisch, señalando que la presión de la clase trabajadora por obtener aumentos de salarios había sido una respuesta a la inflación y no su origen. Por lo tanto, creían que los aumentos debían ser absorbidos por los empresarios o bien debía autorizarse nuevos incrementos de salarios para recomponer su poder de compra ${ }^{30}$.

En cuanto a la inversión extranjera, consideraron que el gobierno debía rectificar la política peronista de aliento a su ingreso en la industria y en la producción de energía. En este sentido, saludaron la anulación de los contratos petroleros firmados por Perón «rechazados por el pueblo argentino duran-

\footnotetext{
28 Liceaga, 1956: 10. Gilbert, Tenewicki y Rougier, 2000: 12.

29 Liceaga, 1956: 13.

30 Junta Consultiva Nacional, 1956: 11.
} 
te su lucha contra la dictadura». Más ampliamente, Alende y López Serrot retomaron la posición radical de rechazo a los empréstitos y la inversión extranjera. «Sostenemos fundamentalmente que nuestro desarrollo económico debe realizarse sobre la base del ahorro nacional y los recursos propios» ${ }^{31}$. Esta postura, que había servido de bandera en su lucha contra el peronismo, se basaba en una irreal perspectiva sobre los problemas de balanza de pagos que sostenía que la Argentina poseía una gran capacidad exportadora. Este optimismo exportador y la confianza en una política de control de importaciones más intensa, aseguraría la provisión de dólares. Para los dirigentes intransigentes si las políticas peronistas de aliento a la inversión extranjera eran repudiables, consideraban que las propuestas de Prebisch a favor del retorno al multilateralismo y la adhesión de la Argentina al FMI constituían medidas que atentaban contra la soberanía económica de la nación.

Como se observa, la intransigencia radical compartía la evaluación crítica sobre la economía peronista, pero al mismo tiempo censuraba las políticas tendientes a la liberalización. Frente a la coyuntura, el radicalismo intransigente reforzó su ideario a favor de la planificación y el nacionalismo económico. Incluso el unionismo, la corriente más conservadora del radicalismo, aunque justificó la devaluación como un instrumento para terminar con diez años de «explotación» del agro, se opuso a la devolución del comercio exterior a las grandes empresas exportadoras, como pedían los liberales, y reclamaba el acceso a la propiedad de la tierra ${ }^{32}$.

Otros sectores del campo progresista presentaron una mirada más crítica de la herencia peronista. En primer lugar, se ubicaba el Partido Socialista, una fuerza que a diferencia de otros sectores progresistas mantendría su vínculo con la tradición liberal de la que se había nutrido desde su origen ${ }^{33}$. Los socialistas compartían los diagnósticos de Prebisch sobre la gravedad de la situación económica al sostener que el país había sufrido «uno de los mayores períodos de empobrecimiento de bienes de producción y de consumo, y de más intensa y peligrosa descapitalización». Pero a diferencia del secretario de la CEPAL proponían intensificar el intervencionismo y aplicar políticas selectivas que permitieran que toda la población contribuyera proporcionalmente para superar la crisis: una profunda reforma impositiva, mediante el aumento del impuesto a los réditos y de los beneficios, y la introducción de nuevos gravámenes que pesaran sobre los terratenientes y quienes habían obtenido ganancias extraordinarias con la devaluación. La acentuación de la interven-

\footnotetext{
31 Ibidem: 29.

32 Ibidem: 84 y ss., dictamen de Miguel Ángel Zavala Ortiz.

33 Sarlo, 2001: 38.
} 
ción estatal debía realizarse en la regulación de los mercados, el control de precios y costos, la elevación de los salarios y la legislación social. Al mismo tiempo, el gobierno debía dar marcha atrás en la política petrolera de Perón, proclamando la nacionalización del petróleo y rechazando cualquier intento de privatización de las empresas públicas ${ }^{34}$. Sobre el controvertido papel del capital extranjero, los socialistas consideraban que teniendo en cuenta la crisis que enfrentaba el país por «la temeraria política económica de la tiranía», se debía acudir al financiamiento público o privado, mediante la firma de empréstitos o el fomento a la inversión extranjera, que debería ser sometido a un estudio específico por la Junta Consultiva.

En las filas del Partido Comunista, los dirigentes compartían las críticas al peronismo pero manifestaron una oposición más dura al Plan Prebisch: «es el plan a través del cual los grandes terratenientes y grandes capitalistas se proponen descargar los efectos de la crisis sobre las espaldas del pueblo trabajador y acelerar el proceso de colonización del país» ${ }^{35}$. Luis Sommi (1956), por ejemplo, sostuvo que si bien durante la década peronista no se había producido un cambio estructural, la economía había hecho progresos con el crecimiento del mercado interno, el desarrollo industrial, la diversificación de la producción agraria y la menor dependencia de los mercados externos. Los comunistas pensaban que la sociedad exhibía una nueva correlación de fuerzas, más favorable a la burguesía nacional, y por lo tanto, reclamaban avanzar en el proceso de industrialización, alentar la nacionalización de sectores industriales y realizar la «reforma agraria». En esta mirada, el balance de la década peronista era más positivo, al menos en el desarrollo de las fuerzas productivas. Por ello, Sommi interpretaba que el Plan Prebisch debía ser rechazado porque su objetivo era retrotraer a la Argentina a los años treinta, consolidar la dependencia con las grandes potencias imperialistas y asegurar el dominio terrateniente. Para Sommi, lo que estaba en crisis era «la vieja Argentina, granja de Europa y colonia financiera de la City y Wall Street» ${ }^{36}$.

Otros intelectuales de izquierda como Abraham Guillén (1956), un anarquista español editor de la revista Economía y Finanzas y que se vincularía al sector más radicalizado del peronismo liderado por John William Cooke, combinarían una dura crítica a los años finales del peronismo con la oposición al Plan Prebisch. La devaluación beneficiaba a los terratenientes y al capital extranjero, trasladando el peso de la crisis a los trabajadores, los industriales

34 Junta Consultiva Nacional, 1956: 65-67, documento firmado por Américo Ghioldi, Alicia Moreau de Justo, Ramón Muñiz y Nicolás Repetto.

35 Partido Comunista, 1956: 23.

36 Sommi, 1956: 8-11. 
y las clases medias. Con sus medidas, Prebisch profundizaba las concesiones que Perón había realizado en el Segundo Plan Quinquenal al capital extranjero y la "oligarquía terrateniente". Para Guillén el programa económico fracasaría, en primer lugar, porque la producción agraria no aumentaría con una devaluación sino mediante la reforma agraria y la mecanización. Además, la ventaja inicial del campo se diluiría cuando los industriales y los trabajadores se lanzaran a la lucha reclamando aumentos de precios y salarios, lo que terminaría por originar una crisis social sin precedentes ${ }^{37}$. Como los comunistas, Guillén consideraba que el desarrollo de las fuerzas productivas y la maduración de la clase obrera y la burguesía industrial conformaban el balance más positivo de la experiencia peronista. Cualquier vuelta atrás estaba llamada a fracasar.

\subsection{Los nacionalistas}

Los nacionalistas interpretaron la crisis argentina de una manera más abarcadora que incluía, pero no se reducía a causas económicas. Esta postura era mucho más pesimista que las provenientes de la izquierda y de la tradición liberal. Mario Amadeo, que se desempeñó como canciller del general Lonardi, ofreció la versión más compleja de esta perspectiva. El dirigente nacionalista caracterizó al peronismo como «una oportunidad perdida» que dejaba como herencia una sociedad dividida, una economía quebrada y la destrucción de las instituciones. El divorcio del pueblo con sus clases dirigentes lejos de ser resuelto por el peronismo, había sido exacerbado hasta el extremo poniendo en peligro a la nación como proyecto. Para Amadeo la economía argentina no podría recuperarse si esa cesura no se eliminaba y se incorporaba a los trabajadores al sistema político ${ }^{38}$. Esta perspectiva estaba lejos de ser intrascendente y sería muy pronto recogida por el grupo de Frondizi que se proponía integrar a los peronistas a la «revolución nacional y popular».

Incluso, los nacionalistas fueron los primeros en oponerse al diagnóstico de Prebisch en el interior del gobierno de la «Revolución Libertadora». En efecto, el grupo que ocuparía el Ministerio de Trabajo y Previsión en 1955, conducido por Luis Cerruti Costa y Rodolfo Bledel, comprometidos con una política de acercamiento al movimiento obrero peronista, impugnó las recomendaciones iniciales de Prebisch y reclamó al equipo económico una política consistente con el mantenimiento de la ocupación y el poder adquisitivo

\footnotetext{
37 Guillén, 1956: 38-44.

38 Amadeo, 1956: 106.
} 
de los salarios ${ }^{39}$. Esta estrategia naufragaría con el derrocamiento de Lonardi, en noviembre de 1955, y el desplazamiento de Amadeo, Cerruti Costa y Bledel del gobierno.

El fracaso de la propuesta integracionista de Lonardi abriría paso a interpretaciones marcadamente contrarias al peronismo que acentuarían el papel de la dimensión política a la hora de analizar el origen de «la crisis argentina». El economista Walter Beveraggi Allende rechazó el diagnóstico de Prebisch que sostenía que el país atravesaba una crisis de desarrollo. En cambio, creía que los problemas se debían al mal desempeño del «institucionalismo económico peronista ${ }^{40}$. El remedio era desarmar el aparato peronista y colocar al estado en condiciones de imponer políticas que promovieran el crecimiento y una mejor distribución del ingreso. Para ello había que proceder a estimular la producción por medio de la reducción de los costos, la baja de los impuestos y del gasto público. En cambio, la devaluación le parecía exagerada y contraproducente por sus efectos sobre la inflación. Beveraggi Allende no encontraba ninguna virtud a la economía peronista. Incluso, sostenía que los salarios no habían mejorado y que era un error pensar que su aumento había sido la principal fuerza impulsora de la inflación ${ }^{41}$. Paradójicamente, la crítica a las políticas peronistas no lo conducía a posturas liberales. Entendía que el país no podría eliminar el control de cambios ni los convenios bilaterales como el mecanismo más eficiente para equilibrar la balanza de pagos y garantizar la importación de maquinarias en un contexto mundial dominado por el proteccionismo agrario. Como veremos, en ese punto coincidía con los radicales y los peronistas.

Sin duda, el más duro balance de la economía peronista y el de mayor influjo en la literatura fue presentado por Julio Irazusta. Para el historiador revisionista, el peronismo era la expresión de la crisis de la clase dirigente local, incapaz de conducir el país a su destino de grandeza. Con Perón, el país había dilapidado la mejor ocasión que había tenido para consolidar su progreso, concluyendo diez años más tarde en «una crisis económica sin precedentes ${ }^{42}$. La explicación residía en la influencia británica sobre la Argentina y en la voluntad de Perón y la clase dirigente de otorgar mayores concesiones a una potencia declinante. Este argumento retomaba el presentado en aquel

39 Informe de los representantes del Ministerio de Trabajo y Previsión en la Comisión Prebisch (7/10/55), reproducido en Bledel, 1972: 107-109, y el testimonio de su actuación, 13-19.

40 Beveraggi Allende, 1956: 4.

41 Ibidem, 1956: 7-34.

42 Irazusta, 1956: 222. 
ensayo fundador del nacionalismo que, junto con su hermano Rodolfo, habían escrito poco después de la firma del Tratado Roca-Runciman en 193343. Perón había remedado al vicepresidente Julio Roca (hijo), que en 1933 había firmado el convenio comercial con Gran Bretaña, condenando a la principal industria del país - la ganadería - al ocaso. La historia de la economía peronista era la historia de «la entrega» a los intereses británicos. En ese relato, Irazusta encadenaba a todas las alternativas que había tenido la relación entre ambas naciones: la propuesta de la sociedad mixta para los ferrocarriles, la nacionalización de esas empresas, los acuerdos comerciales con el Reino Unido y la paralización de Yacimientos Petrolíferos Fiscales.

La reseña de las concesiones al Reino Unido era acompañada por la crítica a las otras dimensiones de la economía peronista. La industrialización le parecía una «farsa» que había sido adoptada como programa súbitamente, cambiando una posición de hostilidad o neutralidad hacia la industria durante la Segunda Guerra Mundial. Luego de 1945, el favor oficial se volcó sobre la industria, pero casi como un instrumento para favorecer la ocupación obrera, antes que para liberar al país de la dependencia del extranjero ${ }^{44}$. La redistribución del ingreso tampoco había sido real. Para congraciarse con los trabajadores, Perón había optado por una política de aumentos salariales sin límites. Lejos de responder a una política de justicia social, esos aumentos eran congruentes con la anglofilia de Perón para «agravar la crisis social, impedir la consolidación de la industria naciente, envilecer los precios de la ganadería para alimentar gratis a Inglaterra, y enriquecer a los gobernantes con el despojo de los productores agrícolas» ${ }^{45}$.

Pese a este oscuro panorama, Irazusta proponía soluciones tan sencillas que, como la liberación del comercio de carnes, desmentían la gravedad de su diagnóstico:

Si seguimos malbaratando la carne al cuarto precio del internacional, y en divisas inconvertibles, la crisis general se agravará. Si la vendemos en dólares al mejor postor la podremos resolver en poco tiempo ${ }^{46}$.

Diez años más tarde, Irazusta mantenía su pesimismo. Ni las medidas ensayadas luego de 1955 ni sus ejecutores, entre quienes Prebisch era anatematizado como responsable de dependencia económica argentina del Reino

43 Irazusta e Irazusta, 1934.

${ }_{44}$ Resonancias de esta interpretación se pueden encontrar, entre otros, en Schvarzer, 1996: 190-220.

45 Irazusta, 1956: 183.

46 Ibidem: 226-227. 
Unido, ofrecían al historiador revisionista razones para prever una solución a la «decadencia argentina» ${ }^{47}$.

\subsection{La corriente liberal}

La crítica a la experiencia económica peronista fue ampliamente compartida por el arco opositor que interpretó a ese proceso como una oportunidad desperdiciada para alentar el desarrollo de las fuerzas productivas y mejorar el nivel de vida de la población. Pero la mayor parte de los actores políticos censuraba al peronismo no tanto por sus banderas -interpretadas de diverso modo - sino por sus promesas incumplidas. En cambio, la recusación de los principios del orden económico y social peronista se redujo a una corriente minoritaria de los círculos políticos que sostenía en materia económica posturas liberales. Nadie interpretó mejor esta corriente que Federico Pinedo, quien como ministro de Hacienda había liderado el equipo que junto con Prebisch aplicaron las políticas económicas para enfrentar la Gran Depresión $^{48}$. Para Pinedo el peronismo era, entre otras cosas, un sistema económico que tenía como principio la intervención sistemática del estado en la vida económica. Basado en una «ideología seudoprogresista» que se expresaba en un «dirigismo opresivo y paralizante» cuyos resultados eran el estancamiento económico y la inflación. Por lo tanto, para el ex ministro «Si se quiere desperonizar el país, hay que desperonizar la economía ${ }^{49}$.

Siguiendo la prédica de Friedrich Hayek, Pinedo pensaba que la planificación era incompatible con la democracia y con las libertades individuales. Al observar el escenario internacional le parecía claro que las naciones que más habían progresado desde la Segunda Guerra Mundial - los Estados Unidos y Alemania Occidental- eran los ejemplos más elocuentes de que la economía de mercado constituía el único camino que aseguraba el progreso económico y las libertades individuales. En cambio, la Argentina había ingresado en una etapa de crisis. La economía peronista se había caracterizado por «sus pretensiones socializantes, su pretensiosa planificación autoritaria, su enconada lucha contra la economía basada en el provecho privado, su ojeriza contra el capital, su persecución de capitalistas mayores y menores» ${ }^{50}$. El origen de esa ideología provenía de la ola favorable a la planificación duran-

47 Irazusta, 1972: 201-209.

48 Pinedo fue autor, junto con Prebisch, del Plan de Reactivación Económica de 1940 y ocupó el Ministerio de Economía por tercera vez en abril de 1962.

49 Pinedo, 1956: 175 y ss.

50 Ibidem: 17. 
te la posguerra basada en una errónea apreciación sobre el Gran Depresión. Pero lo que más inquietaba a Pinedo era que el derrocamiento del peronismo no implicaba la caída de esas ideas debido sobre todo al «ambiente de izquierdismo universal en que viven todos los partidos argentinos» ${ }^{51}$.

A fines de 1955, Pinedo había publicado un breve documento donde propuso un conjunto de medidas para la liberación de las fuerzas productivas: devaluación monetaria y liberación del mercado cambiario, levantamiento de las restricciones a las importaciones y a la actividad productiva, eliminación del IAPI, reforma del sistema financiero (que había sido el instrumento para financiar el déficit de las cuentas públicas) y, sobre todo, abolición del control de cambios que permitía al estado redistribuir el ingreso desde el sector primario exportador a la economía urbana. Tomando nota de las transformaciones estructurales que la Argentina había transitado desde la Gran Depresión, Pinedo advertía que no estaba entre sus propósitos exponer a la industria local «a los peligros de las importaciones ilimitadas», pero creía que la tarifa aduanera era el mecanismo más racional y menos permeable a las presiones empresariales para evitar que la industria «se anquilose o se decida a vivir cómodamente explotando a la colectividad» ${ }^{52}$.

En 1957, en ocasión de la derogación de la Constitución de 1949 y la convocatoria a una reforma constitucional, Pinedo pronunció una conferencia con un tono más pesimista. Entonces, dos cuestiones articulaban sus preocupaciones; en primer lugar, trascurrido un año y medio desde el derrocamiento de Perón, la economía no encontraba una fórmula para crecer; en segundo lugar, el papel que tenía el comportamiento de la clase dirigente, esencialmente su escaso apego a la ley, y su impacto sobre las posibilidades de la economía local.

El primer aspecto se revelaba en el lento crecimiento del ingreso nacional en el marco de lo que advertía con razón como el «prodigioso enriquecimiento del mundo». La consecuencia era la pérdida de la privilegiada posición económica que la Argentina había tenido «hasta hace pocos años». En una crítica abierta contra Prebisch y el estructuralismo cepaliano, sostenía que al menos en parte ello se debía al errado enfoque de las políticas públicas, a la idea de que la etapa agroexportadora había sido posible gracias a condiciones extraordinarias y, por lo tanto, irrepetibles como la disponibilidad de una frontera abierta y la demanda mundial de alimentos ${ }^{53}$. Pero también al des-

51 Ibidem: 65 .

52 Ibidem: 186.

53 Pinedo, 1957: 6 y ss. Años más tarde, Pinedo cuestionaría la hipótesis formulada por Prebisch sobre la existencia de una tendencia secular de deterioro de los términos del inter- 
acierto de las políticas económicas del gobierno de Aramburu y la confusión reinante en el escenario político.

Un tema clave como la formación de capital estaba sujeta según Pinedo a viejos prejuicios. Si la Argentina quería retornar a tasas de crecimiento elevadas debía hacer un esfuerzo importante por capitalizarse. Para ello cabían dos alternativas, o bien se recurría al capital extranjero - especialmente el norteamericano - o se buscaba incrementar el ahorro nacional mediante el sacrificio del consumo. Este dilema, que Perón había tratado de desentrañar recurriendo a un camino intermedio, aparecía ahora más intricado. El primer camino parecía oscurecido por «la insensata aversión al capital extranjero» que predominaba entre algunos políticos y «las masas perturbadas por una incesante prédica». La segunda alternativa, que Pinedo identificaba con la vía soviética, también estaba obstruida por la clase dirigente:

La mayoría de las fuerzas políticas argentinas, contando entre ellas algunas que ponen el grito en el cielo ante el anuncio de inversiones extranjeras, no sólo no piensan en favorecer una reducción de los consumos populares sino que proclaman con énfasis su propósito de mantenerlos al nivel actual y de aumentarlos por el equívoco y pernicioso sistema del control de precio y de los subsidios, que naturalmente aumentan la demanda. ¿Es sobre esa base política, con ese elenco de hombres públicos y con la propensión a la continencia oficial y privada que hemos revelado los últimos años y que estamos revelando todavía hoy, que podemos pensar en dotar al país del capital que se requiere con nuestro propio esfuerzo, con nuestros propios medios, contando exclusivamente con el ahorro argentino? ${ }^{54}$

En relación a la segunda dimensión, el persistente desapego de los sectores dirigentes frente a la ley era, en su opinión, la causa fundamental de los males — no sólo económicos - del país. Por esa razón, la decisión del gobierno militar de convocar a una reforma constitucional no podía traer más que consecuencias negativas. Pinedo temía que se introdujeran cambios que limitaran las libertades individuales, especialmente los derechos de propiedad que él creía ya suficientemente recortados por la perduración de las políticas peronistas de congelamiento de alquileres y arrendamientos y el control de cambios $^{55}$. Se trataba de una mirada más pesimista que aquella presentada en septiembre de 1955, y que se fundaba en la perduración de las ideas y prácticas del intervencionismo del estado. El tono pesimista se acentuaría a partir de entonces. Una década después, enfrentando en el plano de las ideas polí-

cambio como principal traba contra el desarrollo de los países primario-exportadores. Pinedo, 1963

54 Pinedo, 1957: 13.

55 Ibidem: 32-40. 
ticas a la dictadura del general Juan Carlos Onganía, Pinedo escribiría uno de sus últimos libros, en el que reivindicó tempranamente la economía primario exportadora al tiempo que identificó al gobierno de Perón como el momento de inicio de la «decadencia argentina» ${ }^{56}$.

Otros economistas liberales como el joven Roberto Alemann compartían las críticas al manejo económico peronista, especialmente el dirigismo «reglamentarista y detallista que todo lo pretendía prever y regular» y la alta inflación. Pero al mismo tiempo, pensaba que el estado estaba llamado a desempeñar un importante papel en la recuperación económica ${ }^{57}$. La distorsión en el funcionamiento de la economía era tal que no podía esperarse que la restauración del libre juego del mercado, solucionara todos los problemas. Era necesaria una activa política económica que mediante políticas monetarias, aduaneras, e impositivas permitiera la restauración de los mercados y de los comportamientos de los empresarios y consumidores distorsionados por el «dirigismo peronista».

En acuerdo con Prebisch, Alemann señalaba para el estado tareas esenciales para reiniciar el crecimiento como una política industrial que alentara la sustitución de importaciones en las ramas básicas como la siderurgia y la química. Más importante aún, era el papel que el estado debía desempeñar en el plano de la formación de capital. Para Alemann (1956), lo que el país necesitaba era una política de inversiones que quebrara la propensión dominante a consumir, aún entre los sectores de mayores ingresos, y posibilitara el aumento del ahorro y la inversión. Por supuesto, el país no podría dejar de recurrir al financiamiento externo - la inversión directa y los préstamos de los organismos internacionales - pero la posibilidad de retomar el sendero del crecimiento sostenido residía en la restauración de la capacidad de ahorro de la economía nacional. Como se observa, la postura de este joven economista parecía estar más en sintonía con los debates internacionales y con la aceptación de que si la planificación de posguerra era indeseable, la intervención del estado constituía un instrumento esencial para superar las trabas al desarrollo.

56 Pinedo, 1968: 147-156 y 185-199. Esta mirada sería retomada en la historiografía por Díaz Alejandro, 1975. También por Lewis, 1993.

57 Alemann, 1955: 490-493. Economista formado en la Universidad de Berna, Alemann fue consejero financiero de la Embajada en Londres (1956), asesor del Ministerio de Economía (1958) y ministro de Economía entre 1961 y 1962 y durante la última dictadura militar (1981-1982). 


\subsection{La respuesta peronista}

Mientras que amplios sectores políticos compartían una mirada crítica sobre la herencia del peronismo, muy pronto desde ese movimiento político se inició la reivindicación de la experiencia de gobierno. El caso más conocido fue el de Arturo Jauretche, ex presidente del Banco de la Provincia de Buenos Aires, cuya intervención es tradicionalmente vista como la única respuesta desde el peronismo ${ }^{58}$. En efecto, la publicación de El Plan Prebisch. Retorno al coloniaje (1955) inauguró esta mirada, constituyendo un jalón clave en la trayectoria de ese autor, que a finales de los años sesenta se convertiría en uno de los ensayistas de mayor resonancia del revisionismo histórico. Jauretche acusó a Prebisch por presentar un balance negativo basado en un análisis malicioso de las estadísticas para justificar una «contrarrevolución económica», consistente en el retorno al orden político y económico clausurado en 1943, que él identificaba con el predominio de los intereses agrarios. Se buscaba destruir la industria e imponer políticas favorables al agro, lo que generaría miles de desocupados ${ }^{59}$. Según Jauretche, la economía argentina afrontaba algunos problemas estructurales pero estaba lejos de padecer una crisis. Sostenía que el peor momento había sido 1952, pero tres años más tarde la economía se había recuperado. ¿Cómo podía interpretarse que los índices de la producción agraria e industrial, el consumo y la inversión fueran positivos? Esta mirada constituía un balance más ajustado que ha sido rescatado por Gerchunoff y Antúnez (2002: 197). Pero la popularidad del planteo de Jauretche se debió sobre todo a ligazón que hizo entre el Prebisch de los años treinta y el consejero económico de la «Revolución Libertadora», lo que condenaría al más importante economista argentino del siglo XX a un ostracismo interno.

Como dijimos, la intervención de Jauretche no fue la única entre los peronistas, aunque su posterior trayectoria en el «pensamiento nacional» ensombreció otras voces. El propio Perón intervino activamente, algo que ha sido subestimado por los revisionistas proclives a presentar a Jauretche en una posición más central de la que tenía en el peronismo en los años cincuenta. En enero de 1956, el ex presidente publicó La fuerza es el derecho de las bestias donde presentaba una versión algo fantasiosa de la economía peronis-

58 Altamirano, 2001: 52-53. Gilbert, Tenenwicki y Rougier, 2000: 7. Estos últimos autores además presentan a Jauretche como un "claro referente del pensamiento "nacional" y "popular"», una identidad que se construiría con posterioridad, durante los años sesenta.

59 Jauretche, 1955: 9-10. 
ta y censuraba a Prebisch por intentar presentar una crisis «que no existe» ${ }^{60}$. Poco después, volvió a acusar a sus sucesores de falsear la realidad económica con el objetivo último de derrumbar el nivel de vida popular y «entregar la economía del país al extranjero». Para él la rebelión había sido financiada por los exportadores de manufacturas inglesas y norteamericanas para quienes la industrialización había significado la pérdida del mercado local ${ }^{61}$.

En 1957, desde Venezuela, Perón diagnosticó que la Argentina padecía una crisis de equilibrio, por la falta de una política económica coherente. El Informe Prebisch le parecía de «una ingenuidad y desconocimiento enervantes». La inflación, la desocupación industrial y la crisis de divisas era el resultado del desmanejo económico. Concluía que «los que trabajan con más acierto para mi retorno son los que están en la Casa Rosada» ${ }^{62}$.

Otros ex funcionarios peronistas rechazaron el balance negativo de Prebisch y las fuerzas no peronistas. El Economista, semanario fundado en 1950 por el ex primer ministro yugoslavo Milan Stojadinović que se había exiliado en Buenos Aires, fue una de las principales usinas de defensa de las ideas a favor de la planificación y el desarrollo industrial. Los economistas Antonio Cafiero y Carlos Correa Ávila, bajo seudónimos, publicaron notas en el semanario, algo excepcional debido a las persecuciones contra los peronistas.

Cafiero, ex ministro de Comercio Exterior entre 1952 y 1955, focalizó su atención sobre dos aspectos centrales de las políticas del peronismo: la política de precios agrarios y el fomento de la industria. En cuanto a la primera, defendió la tarea realizada por el IAPI que, inspirada en instituciones similares de Estados Unidos, Canadá y Australia, había permitido eliminar la intervención de las grandes empresas comercializadoras «que disminuían el valor de la producción». Además, el organismo había evolucionado dando creciente lugar a las cooperativas en la comercialización de la producción. Esta había sido su principal tarea como ministro y la que tuvo efectos más importantes. Cafiero concluía que la eliminación del IAPI y el propósito oficial de defender

60 Perón, 1958: 101. El libro sería censurado por los antiperonistas, incluso por quienes como Rogelio Frigerio auspiciarían la integración del peronismo a un «frente nacional y popular» conducido por Frondizi. "Perón se olvida en el libro hechos de gran importancia", Qué sucedió en 7 días, 8 de febrero de 1956: 3-6. Para un análisis de las ideas de Perón en torno a la crisis económica y política argentina durante los años de su exilio véase, Belini, 2017.

61 Juan Perón, "La situación argentina", 1956, Archivo Hoover Institution, Stanford University, Colección Juan D. Perón, box 8, folder 10.

62 Juan Perón, “¿Qué pasa con la economía argentina?”, 1957, Archivo Hoover Institution, Stanford University, Colección Juan D. Perón, box 8, folder 13. 
a los productores eran incompatibles ${ }^{63}$. Poco después de la devaluación de la moneda y el anuncio de nuevos precios para el agro, el ex ministro censuró el retorno a las prácticas anteriores a 1946 de fijar precios sostén y la fuerte transferencia de ingresos a los productores pampeanos que solo traería inflación, caída del salario real y crisis industrial. En su opinión, la devaluación no era el mecanismo más efectivo para alentar la producción exportable. En cambio era preferible promover la difusión de herbicidas, semillas híbridas y maquinaria agrícola ${ }^{64}$.

En relación al sector industrial, Cafiero sostuvo que si bien la industrialización tenía un origen previo al peronismo, recién a partir de 1946 el gobierno argentino había aplicado una política industrial compuesta por variados instrumentos entre los cuales el uso de la política cambiaria había sido el más eficiente. Respondiendo a las críticas de Prebisch, el ex ministro cuestionaba la idea de la errónea orientación de la política industrial al advertir que desde 1949 se venían alentando las industrias de bienes de consumo durables y, con el auxilio del capital extranjero, las ramas más complejas. La imagen que presentaba era la de un lento cambio estructural que ponía de manifiesto el propósito oficial de abandonar la orientación agroexportadora. De todas formas, Cafiero reconocía que el proceso de «integración industrial» enfrentaba duras restricciones en la producción de energía, la importación de insumos básicos y la descapitalización del sistema de transporte ${ }^{65}$.

A comienzos de la década de 1960, Cafiero publicó el primer análisis sistemático sobre la economía peronista, mostrando sus luces y sombras. La década peronista constituía "una vasta y rica experiencia», que se había apartado del liberalismo y que podía servir de base para desarrollar una «doctrina económica propia». Nuevamente aquí se observa la falta de reconocimiento a las ideas cepalianas como base para pensar los problemas de la estructura económica argentina. Más interesante aún es cómo las dificultades económicas posteriores a 1955 le permitían a Cafiero proponer la idea de que la crisis se había iniciado con el derrocamiento del peronismo y no debido a sus políticas:

63 Frank Tonytrade, "La disolución del IAPI y el comercio interno de granos", El Economista, 19 de noviembre de 1955: 4.

64 Frank Tonytrade, "La nueva política agraria y los precios de estímulo", El Economista, 26 de noviembre de 1955: 4. Esta postura retomaba la sostenida por equipo económico peronista a partir de 1952. Belini, 2014: 112-114. Paradójicamente, Cafiero había propuesto entonces la devaluación monetaria.

65 Frank Tonytrade, "Estructura y ritmo de la industrialización", El Economista, 7 de enero de 1956: 4. 
Han pasado cinco años desde la revolución de septiembre de 1955. No es un lapso corto. En el mismo espacio de tiempo, que corrió después de 1945, el país modificó radicalmente su estructura económica y social, desarrolló y consolidó una poderosa industria manufacturera, rescató totalmente su deuda externa, modificó sustancialmente el esquema de sus relaciones sociales. Se arguirá que todo fue posible porque el país había emergido de la guerra con casi 1.600 millones de dólares. ¿Pero acaso los 2.000 millones de dólares de deuda externa, que el país debe actualmente y que no debía en 1955, no equivalen a algo mucho mayor que aquella masa de reservas, constituida en gran parte por divisas bloqueadas o inconvertibles, acumuladas a costa de la severa descapitalización durante los años que duró la Segunda Guerra Mundial?66

La intervención de Correa Ávila se focalizó, primero, en discutir los diagnósticos de Prebisch y el inventario que los antiperonistas realizaban de «la Segunda Tiranía». En segundo lugar, se convirtió en un duro opositor del abandono del comercio bilateral y la firma de los acuerdos con el Club de París. Sus posturas tenían origen en su participación como integrante de la Revista de Economía Argentina dirigida por Alejandro Bunge, y su experiencia como director general de Comercio Exterior y vicepresidente del IAPI durante el segundo gobierno de Perón ${ }^{67}$.

Como Liceaga y Jauretche, Correa Ávila entendía que el diagnóstico de Prebisch no se fundamentaba en la realidad económica. No se podía pensar que la Argentina enfrentaba una crisis severa, más adecuado era sostener que se trataba de un impasse estructural, con algunos desequilibrios en la inversión y el consumo. Además los desajustes cuyo origen Prebisch pretendía atribuir a la mala conducción económica eran principalmente resultado de factores que, como el deterioro de los términos del intercambio y las sequías, escapaban a la influencia del gobierno de Perón ${ }^{68}$. En cambio, acordaba en que el principal problema del país era la descapitalización, que interpretaba como el resultado del deterioro de los términos del intercambio «pues como lo ha afirmado el mismo profesor Prebisch en sus informes de la CEPAL, existe una marcada correlación entre ese índice y la tasa de inversión» ${ }^{69}$. Para resolver ese problema, Correa Ávila postulaba la necesidad de recurrir a empréstitos o bien al ingreso de capitales extranjeros.

Si para el ex funcionario era claro que el país debía hacer un importante esfuerzo para acelerar el crecimiento, Prebisch ignoraba los cambios estruc-

66 Cafiero, 1961: 17. Cafiero llegaría a ser ministro de Economía en 1975 y gobernador de la provincia de Buenos Aires entre 1987 y 1991.

67 Belini, 2006: 27-50.

68 Economicus, 1956: 11.

69 Ibidem: 17. 
turales alentados por el peronismo; en primer lugar, el cambio en la composición de los pasivos externos, donde se habían liquidado los compromisos financieros por el pago de la deuda externa y los servicios de fletes y seguros. Es decir, la economía local había ganado en autonomía y su composición de los pasivos había perdido rigidez. En segundo lugar, por el avance de la industrialización que operaba en el mismo sentido. Prebisch prefería despreciar esos cambios, al sostener que no se habían desarrollado las industrias básicas. Según Correa Ávila, era «un planteo absurdo» pensar que primero debían desarrollarse esas industrias y solo después las ramas «livianas». Por último, Prebisch no reconocía la redistribución del ingreso que si había sido excesiva en detrimento de la inversión, al mismo tiempo permitía contar con «una población más alimentada, mejor vestida y con más viviendas que hace diez años».

Según Correa Ávila las medidas propuestas por Prebisch serían contraproducentes para sus propósitos. La devaluación provocaría un incremento de la inflación que lejos del $10 \%$ programado no estaría por debajo del $30 \%$. A diferencia de Prebisch, el autor entendía que era ilusorio esperar que en ese marco inflacionario y de liberalización de precios, los empresarios absorbieran los mayores costos. Por último, la propuesta de alentar la producción de granos contradecía el análisis de la CEPAL sobre la situación del mercado mundial de trigo marcado por una oferta excedente ${ }^{70}$.

Como experto en comercio exterior, Correa Ávila criticó también la propuesta de un retorno al comercio multilateral. En primer término porque ello obligaba a consolidar deudas comerciales de mediano plazo, convirtiéndolas en deudas financieras. En segundo lugar por las dificultades del comercio mundial. «Es absurdo un retorno al multilateralismo a todo trapo en una economía internacional que se caracteriza en la mayoría de los países por las prácticas dirigistas, la escasez de dólares, los procedimientos discriminatorios para exportar excedentes exportables y la política que se realiza en materia de productos alimenticios ${ }^{71}$. No estaba en desacuerdo con el regreso parcial al sistema multilateral, pero ello debía hacerse cuidadosamente, manteniendo los acuerdos bilaterales que habían permitido el incremento del comercio con las naciones de Asia, América Latina y la Europa oriental, para evitar retornar a una dependencia de los mercados de Europa occidental. Estas prevenciones resultaron bastante más acertadas de las dificultades de las negociaciones y concesiones argentinas con el Club de París. Finalmente, cuando se conocie-

\footnotetext{
70 CEPAL, 1959: 42-43.

71 CCA, "Resultados de la nueva política comercial argentina", El Economista, 29 de diciembre de 1956: 4.
} 
ron el acta de París y el acuerdo de Bonn, Correa Ávila señaló que se estaba retrocediendo en materia de comercio exterior ${ }^{72}$.

Al evaluar los resultados de la política económica del gobierno militar, Correa Ávila sostenía que mostraban que el diagnóstico de Prebisch había sido errado. Entre 1955 y 1957, el ritmo de crecimiento del PBI per cápita se había desacelerado aún más. Los incentivos seleccionados habían fracasado; ni la producción agraria ni las exportaciones se habían incrementado. En cambio, la devaluación había alentado la inflación y no había resuelto la crisis del balance de pagos. Ello conducía al economista social católico a un moderado pesimismo exportador. La conclusión le parecía clara y paradójicamente estaba en línea con las ideas de Prebisch: "Quiere decir entonces que solo mediante la industrialización se puede lograr un crecimiento estable del ingreso nacional» ${ }^{73}$.

\section{LA FALLIDA SÍNTESIS FRONDICISTA}

Mientras se discutían las causas de la crisis y los fundamentos del Plan Prebisch, Frondizi iniciaba su carrera para convertirse en candidato presidencial. En enero de 1956, conoció a Rogelio Frigerio, un ambicioso empresario y ex militante comunista que influiría sobre el pensamiento del dirigente radical dando nacimiento a una nueva estrategia política y económica que se conocería como desarrollismo ${ }^{74}$. Dos dimensiones clave de esta postura eran el «integracionismo»y, en el orden económico, una nueva amalgama de ideas que ponían el eje sobre la necesidad de impulsar la industrialización. La primera dimensión implicaba el reconocimiento de que la resolución de la crisis política y social demandaba la integración de las masas peronistas al orden democrático. Frondizi era el primer dirigente que reconocía que la desperonización había fracasado. Claro que Frondizi y Frigerio se proponían capitalizar en su favor la integración de los peronistas a un nuevo «frente nacional y popular». La segunda dimensión, la propuesta económica, implicaba tirar por la borda el discurso anti-imperialista y el ideario estatista e intervencionista de la intransigencia radical. Y esta operación se produjo a espaldas de

72 CCA, "El multilateralismo y las Actas de París", El Economista, 2 de noviembre de 1957: 1-4.

73 CCA, "Lento desarrollo económico y social", El Economista, 17 de julio de 1957: 3.

74 La bibliografía sobre Frondizi y el desarrollismo es extensa e imposible de citar aquí. Sobre el tema véase Sikkink, 1991. Szusterman, 1998. Altamirano, 2001: 54-69. Spinelli, 2005: 249-263. 
la Unión Cívica Radical Intransigente y de sus seguidores. Ambos aspectos de la propuesta (uno proclamado abiertamente por el candidato y el otro sólo conocido por fórmulas que permitían ocultar cuánto de ese ideario estaba cambiando) fueron efectivos a la hora de capitalizar apoyos de diversos actores y sumar a dirigentes peronistas como Jauretche o nacionalistas como Amadeo y Correa Ávila al «movimiento nacional», a través de la revista Qué de Frigerio.

Según el diagnóstico de Frondizi y Frigerio, la Argentina enfrentaba una crisis de desarrollo; el sector agrario exportador se encontraba estancado y no lograba generar las divisas que el desenvolvimiento de la economía requería, al tiempo que el desarrollo industrial demandaba mayores divisas para importar combustibles, insumos básicos y maquinarias. Asumiendo como un dato la tendencia secular al deterioro de los términos del intercambio que perjudicaba a las economías primario exportadoras, el desarrollismo sostenía como la CEPAL que la Argentina estaba condenada a la crisis crónica de su balanza de pagos $^{75}$. Como advertía Frondizi:

Las actuales exportaciones argentinas apenas reditúan al país 1.000 millones de dólares anuales. Si se pretendiera prescindir de la industria nacional y adquirir en el extranjero todos los artículos que nuestra industria proporciona al mercado interno, sería menester elevar esas exportaciones a 7.000 millones de dólares. Ni nuestra inmediata capacidad de producción agropecuaria autoriza a soñar con tamaña fantasía ni, en el mejor de las hipótesis, hallaríamos hoy un mercado dispuesto a absorber tan enorme masa de artículos a los precios actuales ${ }^{76}$.

En consecuencia, la resolución del estrangulamiento del sector externo, la generación de empleo y el incremento de la renta nacional sólo podría alcanzarse si se lograba imponer un programa de industrialización diversificado que, como sostuvo Di Tella, resultó más autarquizante que el propuesto por el peronismo. En este punto, el planteo se apartaba de las ideas sostenidas por Prebisch y la CEPAL que a mediados de la década de 1950, reconocían la importancia de alentar el comercio interregional de manufacturas como una vía para eludir los límites de mercados internos estrechos ${ }^{77}$.

Ahora bien, teniendo en cuenta que el desarrollo de las industrias básicas implicaba grandes inversiones y el control sobre tecnologías complejas, ¿cómo financiar ese salto cualitativo que implicaba la industrialización? Para Fron-

75 Frigerio fue un crítico acérrimo de la CEPAL y de Prebisch en particular, negando cualquier influencia sobre el desarrollismo argentino. Frigerio, 1967: 65-71.

76 Frondizi, 1957: 59-60.

77 Di Tella, 1979: 174. CEPAL, 1956. 
dizi y Frigerio, la economía argentina tenía una baja capacidad de ahorro interno, por lo tanto había que alentar la inversión de capitales extranjeros. Se trataba de un giro dramático de su discurso, que Frondizi asumió con la fe de un converso.

Finalmente, al enfrentar una nueva crisis de balanza de pagos a fines de 1958, Frondizi y Frigerio completaron su giro ideológico al acordar con el FMI un plan de estabilización que implicó una gran devaluación monetaria, la liberación del mercado cambiario, la reducción de los gastos públicos y un programa de privatizaciones. La ejecución del plan fue puesto en manos de economistas ortodoxos, aquellos con los que Frondizi se había enfrentado desde 1955, como Álvaro Alsogaray y Roberto Alemann ${ }^{78}$.

$\mathrm{Ni}$ el giro de las políticas económicas ni el éxito alcanzado en el ingreso de capital extranjero y en el programa de estabilización, evitaron nuevos contratiempos económicos que desencadenaron en una crisis de divisas y una aguda recesión entre 1962 y 1963. La economía argentina que emergió de esa crisis era algo distinta de la que los militares habían heredado en 1955. Una mayor «autarquía industrial» no había resuelto los desequilibrios externos, ni las políticas ortodoxas habían solucionado la persistente inflación. En cambio, la experiencia frondicista dejaba un sector manufacturero con un alto nivel de transnacionalización y una importante deuda externa, planteando problemas algo diferentes de los que Argentina padecía en los años cincuenta. Pero tal vez, lo que ligaba a una y otra Argentina era el fracaso en la búsqueda de una fórmula política posperonista como lo demostró la victoria electoral peronista en las elecciones para gobernadores realizadas en marzo de 1962, que provocó semanas más tarde el derrocamiento de Frondizi. La síntesis frondicista, que combinaba de manera contradictoria la construcción de un «frente nacional y popular», con un programa económico ortodoxo y un proyecto de industrialización diversificada con auxilio del capital extranjero, había fracasado.

\section{Balance De Un DEBATE INCONCLUSO}

El derrocamiento de Perón reanudó los debates sobre el perfil y el destino de la economía argentina. La presentación del Plan Prebisch, entre octubre de 1955 y enero de 1956, constituyó la oportunidad para que distintos sectores políticos analizaran la coyuntura económica y revisaran, más ampliamente, la herencia legada por casi diez años de gobierno peronista. En este trabajo

78 García Heras, 2008: 61-90. 
hemos reseñado esas discusiones tomando en cuenta cuatro tradiciones ideológicas.

Una primera conclusión que se deriva de estas controversias permite afirmar que las primeras lecturas que se hicieron sobre la economía peronista estuvieron marcadas por las urgencias de la coyuntura. Es decir, el debate sobre el manejo económico del peronismo se confundió con las propuestas de Prebisch para enfrentar los problemas del sector externo. Con la lógica excepción de los peronistas, se bosquejó una primera imagen que reflejaba un amplio consenso sobre los errores y las fallas de la administración de Perón. Las dificultades económicas se atribuían a los diagnósticos errados, la mala conducción o la corrupción del gobierno peronista. Los desafíos que enfrentaba la Argentina como las dificultades propias de una economía semi-industrializada, el estancamiento del agro pampeano y las tendencias del mercado mundial de granos durante la década de 1950, temas que aparecían más claramente en los informes de Prebisch, apenas eran percibidos por el conjunto de los actores políticos. Y cuando se los lograba identificar, eran analizados en otros registros como sucedió con la cuestión del capital extranjero, percibido en términos de la dependencia económica. Por su parte, el peronismo, sometido a una fuerte persecución, ofreció diversas respuestas al debate; la más conocida por su trayectoria política e intelectual en los años sesenta fue la de Jauretche, pero esa intervención si bien fue la más efectiva, no fue la más iluminadora. En cambio, las participaciones de Cafiero y Correa Ávila, olvidadas por la historiografía, mostraban la complejidad de los dilemas económicos y el conocimiento basado en la experiencia de gobierno. En conjunto, los analistas partían del supuesto de que la Argentina tenía una importante capacidad de reacción frente a esas dificultades. Si el tono de algunas intervenciones era sombrío, casi todos pensaban que el sendero de progreso podía ser retomado rápidamente.

El análisis de las controversias de 1955 muestra que en la Argentina de los años cincuenta los programas económicos basados en una intensa intervención estatal y la planificación constituían principios compartidos por amplios sectores políticos. Con la excepción de los liberales representados por Pinedo, desde las izquierdas a las derechas parecía perdurar la confianza en que la mano visible del estado debía y podía reemplazar exitosamente a las fuerzas del mercado. Si como interpretaban muchos el peronismo había conducido a la Argentina a una crisis, ésta no se debía principalmente a los principios económicos que había levantado, sino sobre todo a su mala implementación. Así por ejemplo, las distintas corrientes del radicalismo confiaban en que el estado estaba llamado a cumplir un papel central en la economía y que la planificación era un instrumento esencial para derribar las trabas al 
crecimiento o bien para asegurar la equidad en la distribución del ingreso. Solo Pinedo rechazaba esas concepciones, desde un lugar más marginal incluso que el que ocupaban sus referentes internacionales.

El consenso sobre el papel central del estado en la economía remitía más a las concepciones económicas de la inmediata posguerra que a las recientes teorías del desarrollo. Entre estas últimas, la ausencia más destacada era la del estructuralismo cepaliano cuya influencia - como han sostenido varios analistas - resultó ser muy débil en el escenario local. Que los contrincantes de los debates apenas recurrieran a alguna referencia internacional parece mostrar que el aislamiento ideológico de la Argentina era más amplio que el que se advierte a partir del clásico ejemplo de Prebisch. De todas formas, la mayoría de los participantes en esos debates eran actores políticos. En esos años, el campo de los economistas estaba adquiriendo mayor densidad con la creación de la carrera de economía y la vinculación de viarias universidades argentinas con prestigiosas universidades de Chicago, Cambridge y Oxford ${ }^{79}$. Los años iniciales del posperonismo fueron también los del comienzo de la actuación pública de una nueva generación de economistas que tendrían un papel más destacado en las siguientes décadas.

Los participantes de los debates identificaron un conjunto de factores que serían retomados por la historiografía económica sobre el siglo XX: el deterioro de los términos del intercambio, el derrumbe de la capacidad para importar y la perduración del latifundio ocuparían un lugar destacado en la interpretación que Aldo Ferrer haría en La economía argentina (1963), donde la etapa peronista perdería especificidad como tal para quedar divida entre el período de la ISI «fácil»(1930-1950), y el período de la ISI «compleja»; la errónea orientación de las políticas económicas en la posguerra y el cierre de la economía, conducirían a Díaz Alejandro (1970) a pensar la economía peronista como «una respuesta tardía a la Gran Depresión»; las distorsiones provocadas por las políticas intervencionistas y las transformaciones del marco institucional, han sido revalorizadas en las interpretaciones de Cortes Conde (2006) y Llach y Lagos (2014); la ausencia de una clase dirigente (o de una "burguesía nacional") y la claudicación frente al capital extranjero presente ya en las explicaciones marxistas contemporáneas sobre los límites reformistas del peronismo, han sido resaltadas una y otra vez por autores como Schvarzer (1996) y Basualdo (2006), entre otros.

En las últimas décadas, el lugar central que ocupaba la experiencia peronista a la hora de explicar los problemas de la economía argentina (como en 1955), cedió paso a interpretaciones más complejas. Tomando nota de que,

79 Fernández López, 2001. 
entre 1974 y 1994, la Argentina padeció dos «décadas perdidas»; y del sucesivo fracaso de las estrategias neoliberales y neopopulistas, nuevas miradas han descentrado al peronismo del lugar que tradicionalmente se le adjudicaba en «la declinación argentina». En la base de estas interpretaciones se encuentra la certidumbre de que si la economía peronista presentó sus particularidades, forma parte de una trayectoria común de las naciones latinoamericanas. Tal vez, esa operación intelectual nos permita comprender mejor la naturaleza de la economía peronista y su papel a la hora de explicar el complejo desempeño de la economía argentina en el siglo XX.

\section{BIBLIOGRAFÍA Y FUENTES IMPRESAS}

Alemann, Roberto, "Problemas de la Reorientación de la Política Económica Argentina", Boletín de la Cámara de Comercio Argentino Alemana, 47 (Buenos Aires, 1955): 490-493.

Alemann, Roberto, Cómo superar la crisis económica actual. Hacia una política argentina de inversiones, Buenos Aires, Selección Contable, 1956.

Alonso, Guillermo, "Introducción", El Plan Prebisch de 1956, Buenos Aires, Biblos, 1989: 3-14. Cuadernos de Historia Argentina.

Altamirano, Carlos, Bajo el signo de las masas, Buenos Aires, Ariel, 2001.

Altamirano, Carlos, Peronismo y cultura de izquierda, Buenos Aires, Siglo XXI, 2011.

Amadeo, Mario, Ayer, Hoy, Mañana, Buenos Aires, Ediciones Gure, 1956.

Basualdo, Eduardo, Estudios de historia económica argentina, Buenos Aires, Siglo XXI, 2006.

Belini, Claudio, "El grupo Bunge y la política económica del primer peronismo, 1943-1952”, Latin American Research Review, 41/1 (Austin, 2006): 27-50.

Belini, Claudio, "Controversias y oscilaciones de la política industrial: de Perón a Frondizi”, M. Rougier (comp.), Estudios sobre la industria argentina, Carapachay, Lenguaje Claro, 2013: 117-162.

Belini, Claudio, "Inflación, recesión y desequilibrio externo. La crisis de 1952, el plan de estabilización de Gómez Morales y los dilemas de la economía peronista", Boletín del Instituto de Historia Argentina y Americana Dr. Emilio Ravignani, 40 (Buenos Aires, 2014): 105-148.

Belini, Claudio, "El problema argentino según Perón. Economía y política en el pensamiento del líder justicialista en el exilio", José Carlos Chiaramonte y Herbert 
S. Klein (coords.), El exilio de Perón. Los papeles del archivo Hoover, Buenos Aires, Sudamericana, 2017: 15-58.

Belini, Claudio y Korol, Juan Carlos, Historia económica de la Argentina en el siglo XX, Buenos Aires, Siglo XXI, 2012.

Beveraggi Allende, Walter, El dilema económico de la Revolución, Buenos Aires, 1956.

Bledel, Rodolfo, La economía argentina, 1952-1972. Aplicación constante de la política de libre empresa. La confesión de Prebisch, Buenos Aires, Juárez Editor, 1972.

Bulmer Thomas, Victor, The Economic History of Latin America since Independence, Cambridge, Cambridge University Press, 1994.

Cafiero, Antonio, Cinco años después..., Buenos Aires, Talleres El Gráfico, 1961.

CEPAL, Comisión Económica para América Latina, Exposición del Dr. Raúl Prebisch, Director Principal a cargo de la Secretaría Ejecutiva, en la sesión inaugural del 19 de noviembre de 1956, Santiago de Chile, 1956.

CEPAL, Comisión Económica para América Latina, Economic Survey of Latin America. 1957, New York, Naciones Unidas, 1959.

CEPAL, Comisión Económica para América Latina, América Latina. Relación de precios del intercambio, Santiago de Chile, 1976.

CEPAL, Comisión Económica para América Latina, Cincuenta años de pensamiento de la CEPAL, 2 vols., Santiago de Chile, Fondo de Cultura Económica, 1998.

Comisión Asesora Honoraria de Economía y Finanzas, Dictamen sobre el Plan de Restablecimiento Económico, Buenos Aires, 1956.

Cortés Conde, Roberto, La economía política de la Argentina en el siglo XX, Buenos Aires, Edhasa, 2006.

Cusminsky, Rosa, "Debates contemporáneos. Algunas opiniones polémicas sobre la política económica de la Argentina", Revista de la Universidad de Buenos Aires, VII/1 (Buenos Aires, 1962): 129-153.

Della Paolera, Gerardo y Taylor, Alan (eds.), A New Economic History of Argentina, Cambridge, Cambridge University Press, 2003.

Di Tella, Guido, “Controversias económicas en la Argentina, 1930-1970”, John Fogarty, Ezequiel Gallo y Héctor Diéguez (eds.), Argentina y Australia, Buenos Aires, Instituto Di Tella, 1979: 165-184.

Díaz Alejandro, Carlos, Ensayos sobre la historia económica argentina, Buenos Aires, Amorrortu, 1975.

Economicus, Tomás, Radiografía del Informe Prebisch, Buenos Aires, editorial, 1956. 
Eshag, Eprime y Thorp, Rosemary, “Las políticas económicas ortodoxas: de Perón a Guido, 1953-1963”, Aldo Ferrer et al., Los planes de estabilización en Argentina, Buenos Aires, Paidós, 1974: 64-132.

Fernández López, Manuel, "El pensamiento económico", Nueva Historia de la Nación Argentina, tomo VIII, Buenos Aires, Planeta, 2001: 499-523.

Ferrer, Aldo, La economía argentina, Buenos Aires, Fondo de Cultura Económica, 1963.

Ferrer, Aldo, Crisis y alternativas de la politica económica argentina, Buenos Aires, Fondo de Cultura Económica, 1977.

Fitzgerald, E. V. K., "ECLA and the Theory of Import Substituting Industrialization", Enrique Cárdenas, José Antonio Ocampo y Rosemary Thorp (eds.), An Economic History of Twentieth-Century Latin America, vol. 3, Palgrave, New York, 2000: 58-97.

Frigerio, Rogelio, Estatuto del subdesarrollo. Las corrientes del pensamiento económico argentino, Buenos Aires, Jorge Álvarez Editor, 1967.

Frondizi, Arturo, Petróleo y Política, Buenos Aires, Raigal, 1954.

Frondizi, Arturo, Ni odio ni miedo: reconstruir el país, Buenos Aires, SEPA, 1956.

Frondizi, Arturo, Industria argentina y desarrollo nacional, Buenos Aires, Ediciones Qué, 1957.

Furtado, Celso, La fantasía organizada, Buenos Aires, Eudeba, 1988.

García Heras, Raúl, El Fondo Monetario y el Banco Mundial en la Argentina, Buenos Aires, Lumiere, 2008.

Gerchunoff, Pablo, "Peronist Economic Policies, 1946-1955", en Guido Di Tella y Rudiger Dornbusch (eds.), The Political Economy of Argentina, 1946-83, Pittsburgh, University of Pittsburgh Press, 1989: 59-85.

Gerchunoff, Pablo y Antúnez, Damián, "De la bonanza peronista a la crisis de desarrollo", J. C. Torre (dir.), Los años peronistas, 1943-1955, Buenos Aires, Sudamericana, 2002: 124-205.

Gilbert, Jorge, Tenewicki, Marta y Rougier, Marcelo, "Debates en torno a la propuesta económica de Raúl Prebisch, 1955-56", XVII Jornadas Historia Económica Argentina, San Miguel de Tucumán, Asociación Argentina de Historia Económica, 2000 .

Guillén, Abraham, La conspiración de la oligarquía. Radiografía del Plan Prebisch, Buenos Aires, Guitem, 1956.

Halperín Donghi, Tulio, La democracia de masas, Buenos Aires, Paidós, 1972.

Irazusta, Julio, Perón y la crisis argentina, Buenos Aires, La Voz del Plata, 1956.

Irazusta, Julio, Balance de siglo y medio, Buenos Aires, Ediciones La Balandra, 1972. 
Irazusta, Rodolfo e Irazusta, Julio, La Argentina y el imperialismo británico. Los eslabones de una cadena, 1806-1833, Buenos Aires, Ediciones Argentinas Cóndor, 1934.

Jauretche, Arturo, El Plan Prebisch. Retorno al coloniaje, Buenos Aires, 1955.

Junta Consultiva Nacional, Respuesta a la consulta del Gobierno Provisional sobre los Informes "Moneda sana o inflación incontenible" $y$ "Plan de Restablecimiento Económico", Buenos Aires, Imprenta del Congreso de la Nación, 1956.

Lewis, Paul, La crisis del capitalismo argentino, Buenos Aires, Fondo de Cultura Económica, 1993.

Liceaga, José, Apreciaciones sobre el Plan Prebisch, Buenos Aires, edición del autor, 1956.

Llach, Juan y Lagos, Miguel, El país de las desmesuras. Las raíces del retraso de la Argentina, Buenos Aires, El Ateneo, 2014.

Love, Joseph, "Economic ideas and ideologies in Latin America since 1930", Leslie Bethell (ed.), Ideas and Ideologies in Twentieth Century Latin America, Cambridge, Cambridge University Press, 1996: 207-274.

Maddison, Angus, La economía mundial, 1820-1992, París, OCDE, 1997.

Ministerio de Finanzas, Actas del Grupo Económico, Buenos Aires, 1953-1955.

Ministerio de Relaciones Exteriores y Culto, Precios internacionales y desarrollo económico integral, Buenos Aires, 1953.

Partido Comunista, La opinión del Partido Comunista sobre el Plan Prebisch, Buenos Aires, Anteo, 1956.

Peralta Ramos, Mónica, Acumulación de capital y crisis política en la Argentina, 1930-1978, México, Siglo XXI, 1978.

Perón, Juan, La fuerza es el derecho de las bestias, Montevideo, Cicerón, 1958. (Primera ed. de 1956).

Pinedo, Federico, El fatal estatismo, Buenos Aires, Kraft, 1956.

Pinedo, Federico, Condiciones del resurgimiento argentino, Buenos Aires, 1957.

Pinedo, Federico, La CEPAL y la realidad económica de América Latina, Buenos Aires, Centro de Estudios sobre la Libertad, 1963.

Pinedo, Federico, La Argentina en un cono de sombra, Buenos Aires, Centro de Estudios sobre la Libertad, 1968.

Prebisch, Raúl, Informe preliminar acerca de la situación económica, Buenos Aires, Presidencia de la Nación, 1955a.

Prebisch, Raúl, La situación económica del país, Buenos Aires, Presidencia de la Nación, 1955b. 
Prebisch, Raúl, Moneda sana o inflación incontenible. Plan de Restablecimiento Económico, Buenos Aires, Presidencia de la Nación, 1956.

Rougier, Marcelo, La economía del peronismo, Buenos Aires, Sudamericana, 2012. Sarlo, Beatriz, La batalla de las ideas, 1943-1973, Buenos Aires, Ariel, 2001.

Schvarzer, Jorge, La industria que supimos conseguir, Buenos Aires, Planeta, 1996.

Scully, Michael, "What Peron Cost Argentina", Reader's Digest, LXVIII (New York, 1956): 11-12

Sikkink, Kathryn, "The Influence of Raúl Prebisch on Economic Policy-Making in Argentina, 1950-1962”, Latin American Research Review, 23/2 (Austin, 1988): 91-114.

Sikkink, Kathryn, Ideas and Institutions: Developmentalism in Brazil and Argentina, Ithaca, Cornell University Press, 1991.

Sommi, Luis, El Plan Prebisch y el destino argentino, Córdoba, ADER, 1955.

Spinelli, María Stella, Los vencedores vencidos. El antiperonismo y la "Revolución Libertadora”, Buenos Aires, Biblos, 2005.

Szusterman, Celia, Frondizi. La política del desconcierto, Buenos Aires, Emecé, 1998.

\section{ANEXo ESTADÍSTICO}

CUAdro 1: Evolución del PBI PER CÁPITA EN AMÉRICA LATINA EN DÓLARES DE 1990 Y TASA DE CRECIMIENTO ANUAL, 1946-1960

\begin{tabular}{|c|c|c|c|c|}
\hline & Argentina & Brasil & Chile & México \\
\hline 1946 & 4665 & 1460 & 3786 & 1873 \\
\hline 1947 & 5089 & 1477 & 3470 & 1882 \\
\hline 1948 & 5252 & 1553 & 3806 & 1904 \\
\hline 1949 & 5047 & 1614 & 3715 & 1952 \\
\hline 1950 & 4987 & 1673 & 3827 & 2085 \\
\hline 1951 & 5080 & 1702 & 3906 & 2185 \\
\hline 1952 & 4727 & 1751 & 4041 & 2208 \\
\hline 1953 & 4884 & 1782 & 4162 & 2151 \\
\hline 1954 & 4986 & 1845 & 4089 & 2296 \\
\hline 1955 & 5237 & 1923 & 3997 & 2419 \\
\hline 1956 & 5290 & 1894 & 3927 & 2367 \\
\hline 1957 & 5468 & 1992 & 4238 & 2609 \\
\hline 1958 & 5705 & 2110 & 4254 & 2263 \\
\hline
\end{tabular}


CuAdro 1: Evolución del PBI PER CÁPITA en AmÉRICA Latina EN DÓLARES DE 1990 Y TASA DE CRECIMIENTO ANUAL, 1946-1960 (cont.)

\begin{tabular}{|c|c|c|c|c|}
\hline & Argentina & Brasil & Chile & México \\
\hline 1959 & 5245 & 2220 & 4134 & 2656 \\
\hline 1960 & 5559 & 2335 & 4304 & 2781 \\
\hline $1946-1960$ & $1,2 \%$ & $3,4 \%$ & $0,9 \%$ & $2,8 \%$ \\
\hline
\end{tabular}

Fuente: elaboración propia en base a Maddison, 1997.

CuAdro 2: TÉrminos Del InTERCAMbio de AmÉricA LATINA $(1928=100)$

\begin{tabular}{|c|c|c|c|c|c|}
\hline & América Latina & Argentina & Brasil & Chile & México \\
\hline 1946 & 112 & 121 & 56 & 50 & 146 \\
\hline 1947 & 113 & 122 & 63 & 54 & 150 \\
\hline 1948 & 117 & 126 & 62 & 55 & 164 \\
\hline 1949 & 110 & 111 & 70 & 60 & 138 \\
\hline 1950 & 132 & 112 & 95 & 53 & 155 \\
\hline 1951 & 131 & 106 & 83 & 57 & 164 \\
\hline 1952 & 121 & 84 & 88 & 61 & 164 \\
\hline 1953 & 129 & 98 & 92 & 66 & 132 \\
\hline 1954 & 132 & 84 & 107 & 55 & 131 \\
\hline 1955 & 123 & 84 & 93 & 60 & 138 \\
\hline 1956 & 123 & 84 & 93 & 60 & 138 \\
\hline 1957 & 122 & 74 & 88 & 57 & 128 \\
\hline 1958 & 113 & 75 & 73 & 61 & 117 \\
\hline 1959 & 105 & 79 & 70 & 66 & 115 \\
\hline 1960 & 105 & 86 & 72 & 55 & 106 \\
\hline
\end{tabular}

Fuente: elaboración propia en base a CEPAL, 1976.

Fecha de recepción: 9 de junio de 2015.

Fecha de envío de las modificaciones: 11 de enero de 2016.

Fecha de aceptación: 25 de enero de 2016. 


\section{The Prebisch Plan of 1955, Argentina's development dilemmas and the controversies surrounding the economic legacy of Peronism}

This article analyses the controversies surrounding the Prebisch Plan of 1955 and Peron's economic legacy. The paper studies the responses of economists and politicians from four ideological traditions (left, nationalism, liberalism and Peronism) to Raul Prebisch's diagnosis of the state of the Argentine economy. It examines prevailing economic ideas in the Fifties and the limited understanding of the dilemmas of a semi-industrialized economy. It is argued that these debates defined an agenda that would last until the rise of Arturo Frondizi's developmentalism in the late 1950s and, at the same time, have a lasting influence on the historical interpretations of Peronist economics.

KeY Words: Economic Policies; Economic Ideas; Peronism; Argentina. 